\title{
1 Interpreting locomotor biomechanics from the morphology of human footprints.
}

2

3 Kevin G. Hatala ${ }^{\mathrm{a}, \mathrm{b}}$, Roshna E. Wunderlich ${ }^{\mathrm{c}}$, Heather L. Dingwall ${ }^{\mathrm{d}}$, Brian G. Richmond ${ }^{\mathrm{e}}$.

4

5 a Department of Human Evolution, Max Planck Institute for Evolutionary Anthropology,

6 Deutscher Platz 6, D-04103 Leipzig, Germany; ${ }^{\mathrm{b}}$ Center for the Advanced Study of Hominid

7 Paleobiology, Department of Anthropology, The George Washington University, 2110 G St.,

8 NW, Washington, DC 20052, USA; 'Department of Biology, James Madison University, MSC

9 7801, Harrisonburg, VA 22807, USA; ${ }^{\mathrm{d}}$ Department of Human Evolutionary Biology, Harvard

10 University, 11 Divinity Ave., Cambridge, MA 02138, USA; ${ }^{\mathrm{e} D i v i s i o n}$ of Anthropology,

11 American Museum of Natural History, New York, NY 10024, USA

12

13

14

15

16

17

18 *Corresponding author: Kevin G. Hatala

19 Tel: +4903413550358

20 e-mail: kevin.g.hatala@gmail.com

21

22 Main text :

23 Pages: 33

24 Figures: 7

25 Tables: 2

26

27

28

29

30 


\section{Abstract}

Fossil hominin footprints offer unique direct windows to the locomotor behaviors of our ancestors. These data could allow a clearer understanding of the evolution of human locomotion by circumventing issues associated with indirect interpretations of habitual locomotor patterns from fossil skeletal material. However, before we can use fossil hominin footprints to understand better the evolution of human locomotion, we must first develop an understanding of how locomotor biomechanics are preserved in, and can be inferred from, footprint morphologies.

In this experimental study, 41 habitually barefoot modern humans created footprints under controlled conditions in which variables related to locomotor biomechanics could be quantified. Measurements of regional topography (depth) were taken from 3D models of those

41 footprints, and principal components analysis was used to identify orthogonal axes that described

42 the largest proportions of topographic variance within the human experimental sample. Linear

43 mixed effects models were used to quantify the influences of biomechanical variables on the first

44 five principal axes of footprint topographic variation, thus providing new information on the

45 biomechanical variables most evidently expressed in the morphology of human footprints. The

46 footprint's overall depth was considered as a confounding variable, since biomechanics may be

47 linked to the extent to which a substrate deforms. Three of five axes showed statistically

48 significant relationships with variables related to both locomotor biomechanics and substrate

49 displacement; one axis was influenced only by biomechanics and another only by the overall

50 depth of the footprint. Principal axes of footprint morphological variation were significantly

51 related to gait type (walking or running), kinematics of the hip and ankle joints and the

52 distribution of pressure beneath the foot. These results provide the first quantitative framework

53 for developing hypotheses regarding the biomechanical patterns reflected by fossil hominin 
54 footprints by demonstrating the statistically significant effects of specific kinematic variables on 55 patterns of variation in footprint topography.

57 Keywords: Locomotion; Ileret; Laetoli; Kenya

Introduction

Researchers have long recognized (e.g., Lamarck, 1809; Darwin, 1871) that habitual

61 bipedalism is a unique behavioral characteristic that distinguishes modern humans from the other

62 extant great apes and that would have played an influential role in many aspects of our evolution.

63 Yet much remains unknown about this behavior's evolutionary history. Did bipedalism evolve in

64 different ways within the hominin clade? Or did all early hominins walk bipedally in essentially

65 the same manner as modern humans do today?

The locomotor styles of early hominins are often characterized as fitting into one side of

67 a dichotomy, or somewhere along a continuum, between chimpanzee-like facultative bipedalism

68 and human-like habitual bipedalism. However, this paradigm excludes the possibility that forms

69 of habitual bipedal locomotion different from those of any extant species could have evolved

70 throughout the history of the hominin clade. Robinson (1972) and Oxnard (1975) were among

71 the first to hypothesize that the suites of postcranial features within particular fossil hominin taxa

72 could imply locomotor styles that are in some ways similar to, but in other ways quite different

73 from, those that are observed among modern taxa. The discovery of a 3.4 Ma hominin foot from

74 Ethiopia with a startling combination of primitive and derived features previously thought to be

75 incongruous with one another (e.g., a widely divergent hallux alongside other features

76 functionally linked to terrestrial bipedalism) has provided hard evidence to support the 
77 hypothesis that multiple forms of bipedalism must have evolved and persisted within the

78 hominin clade, at least during the Pliocene (Haile-Selassie et al., 2012). This lends support to the

79 idea that the evolution of bipedalism within the hominin clade was a process in which bipedalism

80 formed larger portions of an overall locomotor repertoire in some hominin taxa relative to others

81 (Rose, 1991). This discovery also suggests that we have much left to learn about the timing and

82 nature of the evolution of a human-like form of bipedalism, and raises the question of how we

83 can identify and characterize different modes of bipedalism that existed throughout the

84 evolutionary history of the hominin clade.

85 Many recent hypotheses, and several ongoing debates, regarding the first emergence of a

86

87 distinctly human-like form of bipedalism are centered around the interpretation of locomotor adaptations in two particular taxa, Australopithecus afarensis (dating to c.3-4 Ma) and Homo erectus sensu lato (dating to c.1.9 Ma-50 ka; Wood and Richmond, 2000). The postcranial anatomies of both taxa are relatively well-known compared to those of other fossil hominins and the current evidence even includes well-preserved partial skeletons of both (A.L. 288-1 and KNM-WT 15000[ Johanson et al., 1982, Walker and Leakey, 1993]). However, despite these relatively rich samples of fossil evidence, the interpretation of locomotor patterns practiced by Au. afarensis and $H$. erectus s.l. have been rife with debate.

The postcranial morphology of $A u$. afarensis has been viewed by some as incompatible with a form of bipedalism that directly mirrored that of modern humans (e.g., Jungers, 1982, Stern and Susman, 1983). Yet others have made the argument, based on the same assemblage of fossils, that locomotor adaptations in Au. afarensis bear a striking enough resemblance to those of modern humans that they must have used a similar mode of bipedal locomotion (e.g., Latimer and Lovejoy, 1989, 1990a,b; for a summary of the debate see Ward, 2002). Such debates have 
100 continued with the interpretations of more recently discovered fossils, which have suggested to 101 some, but not others, that Au. afarensis may have had human-like arches in their feet (Ward et 102 al., 2011, but see Drapeau and Harmon, 2012) and had relatively longer legs than previously 103 thought (Haile-Selassie et al., 2011; Pontzer, 2012). Generally, the overall body plan of $H$. erectus s.l., including features such as its limb 105 proportions (Ruff and Walker, 1993; Richmond et al., 2002) and the strength of its humerus 106 relative to its femur (Ruff, 2009), bears a much closer resemblance than $A u$. afarensis does to the 107 pattern observed in modern humans. Combined with the human-like morphology of the $H$. 108 erectus s.l. inner ear and the ape-like morphology found in Australopithecus (Spoor et al., 1994), 109 this evidence suggests to many researchers that H. erectus s.l. may have been the first hominin 110 (or at least the first of those fossil taxa known today) to practice a human-like style of 111 bipedalism. However, the morphology of a 0.9-1.4 Ma pelvis from Gona, Ethiopia, which has 112 been assigned by its discoverers to H. erectus (Simpson et al., 2008), bears some resemblances to 113 Australopithecus fossils (Ruff et al., 2010, but see Simpson et al., 2014) in ways that could imply 114 that the taxonomic allocation of the specimen is incorrect, or that the bipedal locomotion of $H$. 115 erectus was slightly different than that of modern humans.

117 assemblages of fossil skeletal evidence. This problem arises when analyzing an anatomical form 118 from the fossil record that is not identical to the anatomy of any extant taxon (Richmond et al., 119 2012). This typically results in some level of subjectivity when reconstructing the behavioral 120 repertoires of fossil hominins because their anatomies are in some ways similar to, but in other 121 ways very different from, both modern humans and the other extant great apes. 
The debates that have arisen from this approach emphasize the necessity of new objective 123 techniques that can extract direct evidence of biomechanical function from the fossil record. In

124 other words, one needs to identify ways in which biomechanical patterns leave unambiguous

125 signatures that are preserved in the fossil record. While such evidence has been difficult to 126 identify in skeletal material, footprints from the human fossil record offer unique direct windows 127 to the mechanics of extinct hominin locomotion. Skeletal morphology is representative in some 128 ways of habitual activity patterns, yet footprints preserve explicit evidence of locomotor 129 behaviors on an immediate timescale. With footprints, one can be certain of where and how 130 hominins were moving across their landscapes at moments in time millions of years ago.

131 Importantly, the record of pre-Homo sapiens footprints in the human fossil record continues to 132 grow, such that extensive assemblages are now known from both the Pliocene and the early 133 Pleistocene. Hominin footprints dating to c.3.7 Ma were uncovered at Laetoli, Tanzania in the 134 late 1970s (Leakey and Hay, 1979), and in more recent years multiple hominin footprint sites 135 dating to c.1.5 Ma have been discovered and excavated at Ileret, Kenya (Bennett et al., 2009; 136 Richmond et al., 2012, 2014; Dingwall et al., 2013). These sites offer rare opportunities to 137 understand the nature of hominin bipedalism at two very different times in our evolutionary 138 history and to address questions about when a human-like form of bipedalism first emerged. 139 Furthermore, these data will allow us to build new hypotheses regarding the ways in which the 140 ecological, energetic, and other effects of those locomotor patterns may have changed between 141 the Pliocene and the Pleistocene. However, before these data can better inform us of the detailed nature of early hominin 143 bipedalism, we must understand how footprints actually record evidence of locomotor patterns. 144 Beginning with the earliest analysis of the Laetoli footprints (Day and Wickens, 1980), many 
145 researchers compared the shapes of fossil hominin footprints to those produced by modern

146 humans and drew conclusions about foot function or locomotion based on differences in

147 footprint morphology (e.g., Tuttle et al., 1991; Meldrum, 2004; Berge et al., 2006; Bennett et al.,

148 2009; Crompton et al., 2012). These studies have required the assumption that footprint

149 morphologies directly represent particular functional signals, yet this has never been validated

150 experimentally. In order to avoid the same kinds of seemingly unsolvable debates we see in

151 analyses of fossil hominin skeletal anatomy, we must move beyond comparative analyses that

152 treat modern species as directly analogous models and instead understand how particular

153 biomechanical variables influence footprint shape (Richmond et al., 2012). With this

154 understanding of how the biomechanical variables affect variation in footprint morphology, we

155 can then be confident in deriving functional interpretations from footprints that may have been

156 produced by an extinct hominin whose postcranial anatomy did not match that of any living

157 taxon.

Raichlen and colleagues (2010) demonstrated that certain biomechanical variables are

159 tightly linked to footprint morphology, as they showed that one can distinguish between human

160 footprints produced with an extended limb gait and those produced with bent hips and bent

161 knees. But uncovering the relationships between biomechanical variables and footprint

162 morphologies has proven to be complex, as other studies have found that some logically

163 expected relationships were not observed between footprint shape and certain biomechanical

164 variables. For example, D’Août and colleagues (2010) designed experiments to test directly the

165 hypothesis that footprint depths preserve a record of foot function (in the form of the distribution

166 of plantar pressure). They found that only a weak relationship existed between pressure and

167 footprint depth, and suggested caution in directly interpreting foot function from footprints. 

187 footprints are produced?

Bates et al. (2013) addressed the same question with different statistical techniques, and Hatala et al. (2013) conducted similar experiments but with habitually barefoot people making prints in the same cohesive sediments that preserve the 1.5 Ma Ileret hominin footprints. Yet both of these studies still found very similar results to those of D’Août et al. (2010), with weak relationships between the magnitude of normal forces beneath the foot and the depth of footprints in analogous regions. Together, these studies demonstrate that footprints represent a complicated dynamic interaction between anatomical, functional, and sedimentary variables. The interpretation of functional patterns from footprint morphology requires approaches that extend beyond simply translating deep impressions as direct indications of high normal forces.

In this paper, controlled biomechanical experiments were conducted and analyzed in a manner that explicitly examines how variables related to locomotor biomechanics are recorded in, and can be inferred from, patterns of variation in footprint morphology. This included a consideration of multiple kinetic and kinematic variables that could potentially influence the patterns by which the foot applied forces to move across the substrate. To build this understanding, the following three questions were asked: First, in what ways do the morphologies of footprints tend to vary when produced by different people using different gaits (walking and running)? Second, how and to what extent do specific kinetic and kinematic variables affect those patterns of footprint morphological variation? And last, how and to what extent are those relationships influenced by the compliance of the substrate in which the

Based on the results of previous studies, we hypothesized that certain relatively largescale joint motion patterns (e.g., flexion of the hip and knee) would be significantly related to principal axes of footprint shape variation (as found by Raichlen et al., 2010) and therefore most 
191 easily interpretable from footprint morphologies. Meanwhile, finer details of locomotion (e.g.,

192 regional peak pressures) might be less likely to influence principal axes of footprint topographic

193 variation (following D’Août et al., 2010; Bates et al., 2013; Hatala et al., 2013) and are therefore 194 more difficult to infer from footprint shapes.

196 Materials and Methods

197 Experimental subjects

198 Experiments were conducted with habitually unshod and minimally shod subjects from 199 the Daasanach tribe near the town of Ileret, Kenya. The habitually unshod human foot is known 200 to differ both anatomically (Hoffmann, 1905; Wells, 1931; Sim-Fook and Hodgson, 1958;

201 Barnett, 1962; Ashizawa et al., 1997) and functionally (D’Août et al., 2009) from the habitually 202 shod foot. It is critical to conduct these biomechanical experiments with habitually unshod 203 subjects in order for the results to be applicable to the analysis of fossil footprint assemblages 204 such as those at Ileret, Kenya or Laetoli, Tanzania, which were made by barefoot hominins and 205 pre-date the earliest proposed evidence for the habitual use of footwear (c.40 ka, Trinkaus and 206 Shang, 2008).

Twenty-nine adults (15 male, 14 female, ages 18 and above) and twelve children (10

208 male, 2 female, ages 4-15) participated in these experiments. All subjects were recruited, and 209 provided their informed consent to participate, through a protocol approved by the Institutional

210 Review Boards of The George Washington University and James Madison University. All

211 subjects were pooled in this analysis because we sought to uncover generalizable biomechanical

212 relationships that could be detected regardless of the age or sex of an individual producing a

213 footprint. Age and sex may be difficult, if not impossible to know from fossil hominin footprints. 
214 The nature of our analysis accounted for the random effect of subject identity allowing, in a way,

215 for each subject to have a 'baseline footprint' and for us to measure biomechanically-induced

216 deviations from that baseline shape. Furthermore, studies of plantar pressure have revealed no

217 significant between-sex differences in foot function among either children or adults (Hennig et

218 al., 1994; Bosch et al., 2010; Putti et al., 2010, but see Unger and Rosenbaum, 2004) despite

219 some differences in foot anatomy (Wunderlich and Cavanagh, 2001; Bosch et al., 2010). While

220 peak pressures and forces increase with age, the distribution of relative forces across the foot

221 (which we use in this analysis) appears to vary only slightly past the age of 4.5 years (Bosch et

222 al., 2010). Therefore, anatomical differences between subjects due to sex or age should not

223 influence our results.

Experimental setup

The experimental setup (Fig. 1) was the same as one published previously (Dingwall et

227 al., 2013; Hatala et al., 2013). A trackway was cleared in a large, flat and open space adjacent to

228 the site of ongoing fossil footprint excavations at site FwJj14E at Ileret, Kenya. A one-meter-

229 long pressure pad (RSScan International, Olen, Belgium) was placed about eight meters from the

230 start of this trackway. One meter from the end of the pressure pad, a pit was dug that measured

$231150 \mathrm{~cm}$ long, $50 \mathrm{~cm}$ wide, and $15 \mathrm{~cm}$ deep. This pit was then filled with sediment taken directly

232 from a layer (Lower Footprint Layer) that preserves fossil hominin footprints at Ileret, Kenya

233 (Fig. 2). That sediment was variably hydrated before trials such that the overall depths of the 234 experimentally-produced footprints encompassed the range of depths of the fossil hominin 235 footprints preserved at both Ileret and Laetoli. The sediment patch was mixed with a trowel and 236 lightly smoothed after each trial, to minimize compaction over time and provide a clear surface 
237 for the footprint in the subsequent trial. The experimental trackway extended about eight meters

238 beyond the end of the sediment pit. A video camera was placed perpendicular to the trackway, 239 such that it could record all actions that occurred both on the pressure pad and along the patch of

240 hydrated sediment. These experiments were conducted over the course of two field seasons, in

2412011 and 2012. Because of differences in equipment availability, all 2011 trials were recorded at $242210 \mathrm{~Hz}$ and all 2012 trials were recorded at $60 \mathrm{~Hz}$.

243

244 245 246

247

248

249

250

251

252

253

254

255

256

257

258

259

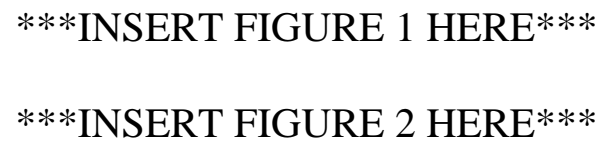

Experimental protocol

The experimental protocol closely resembled one that has been published previously (Dingwall et al., 2013; Hatala et al., 2013). After each subject provided their informed consent to participate, biometric measurements were taken including stature, body mass, functional leg length, and foot length. Fluorescent adhesive markers were placed at the greater trochanter, tibial plateau, lateral malleolus, and fifth metatarsal head of the leg and foot that faced the camera's view. Each subject performed at least six walking trials (three at their normal, preferred speed and three at a faster speed; average walking speed $=1.78 \mathrm{~m} / \mathrm{s}$ ), and six running trials (three at their preferred endurance running speed and three at faster speeds; average running speed $=4.24$ $\mathrm{m} / \mathrm{s}$ ), in which they passed over the entire trackway including both the pressure pad and the hydrated sediment. Trials were discarded and repeated if subjects visibly targeted the pressure pad or sediment patch. In most cases, subjects showed no evidence of targeting the pad or sediment. For example, subjects typically did not contact both the pressure pad and the hydrated 
sediment in the same trial. Additional trials were performed until 3 pressure readings and 3 footprints were generated by each subject at each of the qualitative speeds being examined. Multiple photographs were taken of each footprint such that 3-dimensional models of each one could be rendered using photogrammetry software (PhotoModeler Scanner 2013, EOS Systems, Inc., Vancouver, BC).

There were two trials that seemed successful at the time of experimentation, yet had to be discarded later when poor geometric solutions prevented the rendering of scaled 3-dimensional footprint models by the photogrammetry software. This resulted in a total experimental sample of 490 trials (12 per subject for 41 subjects, minus 2) that were analyzed in this study.

\section{Data processing}

Kinetic and kinematic variables were quantified in each trial. Within RSScan

International Footscan 7 software (Olen, Belgium), peak plantar pressure readings were extracted for 10 regions of the foot: medial and lateral heel, midfoot, metatarsal heads 1-5, the hallux, and the lateral toes. Videos of each trial were digitized in ImageJ software (Rasband, 1997-2012) in order to measure speed, stride length, and stride frequency. MaxTraq software (Innovisions Systems, Inc., Columbiaville, MI) was used to digitize and quantify the angles of the hip, knee, and ankle joints at foot strike, midstance, and toe-off. Using Geomagic Studio (3D Systems, Inc., Rock Hill, SC), the depth of each footprint was measured at 14 functionally-relevant locations: the medial and lateral heel, medial and lateral midfoot, metatarsal heads 1-5, the hallux, and toes 2-5 (Fig. 3). For each model, 25 points were selected along the undisturbed substrate that surrounded the perimeter of each footprint. A least-squares algorithm was used to create a bestfit plane from those 25 points, which represented the ground plane. All depths were measured as 
283 orthogonal distances from this plane. Despite the fact that these are not discrete anatomical

284 landmarks, repeatability tests performed on a subset of 14 footprints revealed that these

285 functionally-relevant locations could be measured in a replicable manner (paired t-test, $p=$

$286 \quad$ 0.7555; mean difference between replicates $=0.005 \mathrm{~cm})$.

287

288

289

290

291

292

293

294

295

296

297

298

299

300

301

302

303

304

305

\section{***INSERT FIGURE 3 HERE***}

D’Août and colleagues (2010) argued that larger individuals have larger feet with greater surface area over which to distribute their weight and the surface area of the foot effectively 'cancels out' the influence of body mass on footprint depth such that the average depth of a footprint is influenced to a larger degree by the compressive strength of the substrate. But foot area may not fully 'cancel out' the effect of body mass on print depth, since body mass ought to scale to the third power and foot surface area to the second. Furthermore, in this study we examined gaits that involve different amounts of force transmission to the ground (i.e., walking and running) and are therefore likely to result in footprints of different depth for the same individual moving across the same substrate. Due to these issues, attempts were made to measure substrate strength directly using a penetrometer. However, obtaining a repeatable measurement across the sediment patch was precluded by heterogeneity of the substrate. As a result, a similar approach to D’Août et al. (2010) was applied, simply to obtain a quantified measure of the amount of sediment displaced in a particular trial due to substrate mechanical, but also biomechanical, factors. The mean of the 14 depth measurements across each footprint was calculated and this measure of substrate deformability was then included in linear models as a variable that could influence footprint topography. 
Analysis - Influences of biomechanical variables on footprint variation

Because a footprint is a complex shape that results from dynamic interactions within the

309 foot but also between the foot and the deforming substrate, there is no reason to expect that the

310 different functional areas from which footprint depth was measured should vary independently.

311 As a result, principal components analysis (using the singular value decomposition) was used as

312 a variable-reduction technique, which provided multiple orthogonal axes along which human

313 footprint shapes were inclined to vary.

The loadings on each principal component were examined to determine the general shape

315 change described by each (e.g., the first principal component was generally characterized by

316 diametric variation in the depth of the forefoot relative to the heel). Biomechanical hypotheses

317 were then developed to explain the ways in which the kinetic and kinematic variables that were

318 quantified in these experiments could induce the types of variation in footprint shape that were

319 described by each principal component axis. Linear mixed effects models were used to assess the

320 competing, but not exclusive, hypotheses for each scenario. In these mixed models, subject

321 identity was designated as a random effect, in a way controlling for anatomical variation and

322 other peculiarities of individual subjects. Mixed effects models did not always result in a

323 statistically significant increase in model fit (evaluated via log-likelihood) compared to standard

324 multiple regression models. However, the inclusion of subject identity as a random effect tended

325 to both eliminate structure from model residuals and decrease the value of the Akaike

326 Information Criterion (AIC) for a given model. Because it is biologically sensible to include the

327 random subject effects in these models, the variable was retained in all cases (following Zuur et

328 al., 2009). 
In the initial phase of this analysis, an inclusive mixed effects model was developed for

each principal component of footprint topographic variation, which included as fixed effects all functional variables that were hypothesized to explain variation along that particular principal component axis. A maximum likelihood approach was used to eliminate variables sequentially if their independent effects were non-significant ( $p>0.05)$; in this process ANOVA was used to compare log-likelihood values of inclusive versus reduced models. Non-significant fixed effects were removed if their absence did not significantly affect the fit of the mixed model and if their removal reduced the value of AIC. The residuals of the final models were examined to ensure that they met the assumptions of normality and homoscedasticity.

The functional variables considered in this analysis of effects on axes of footprint topographic variation included gait type (walking or running), joint angles at foot strike, midstance and toe-off, joint excursions between those three phases, and various measurements of the distribution of peak pressures beneath the foot. It is important to note that in this analysis we were primarily interested in uncovering broad relationships between movement patterns and footprint morphologies. This led us to consider gait type as a categorical variable, rather than speed as a continuous variable. A complete analysis of speed effects within gaits could be a productive target of future work.

\section{Results}

Principal components analysis of the 14 regional footprint depth measurements revealed that only the first five principal component axes individually explained more than $5 \%$ of total variance in footprint topography (Fig. 4). Those first five axes together explained slightly more than $85 \%$ of total variance. Because of their relatively large contributions to describing variance 
352 in footprint topography, these were the axes whose relationships with biomechanical variables

353 were analyzed.

***INSERT FIGURE 4 HERE***

356

The rotation matrix that described the relationships of the original depth measurements to those first five principal component axes was then examined to understand the type of shape variation that each component described (Fig. 5; Table 1). Multiple biomechanical hypotheses were developed to explain variation along each of these principal component axes. Linear mixed effects models were based upon those biomechanical hypotheses.

\section{***INSERT FIGURE 5 HERE*** \\ ***INSERT TABLE 1 HERE***}

The first principal component axis can be summarized as describing depth in the region of the heel versus depth in the forefoot (Fig. 5; Table 1). Through mixed effects modeling, PC1 was found to be significantly influenced by both the total amount of deformation of the substrate and the type of gait used (Fig. 6; Table 2). Variation along the second principal component axis described depth at the first and second toe relative to the heel and lateral metatarsal heads (Fig. 5; Table 1). This component was significantly influenced only by the angular excursion about the hip during the second half of stance (Fig. 7; Table 2). The third principal component described depth at the heel and toes relative to the midfoot and metatarsal heads (Fig. 5; Table 1). This component was affected by only the total deformation of the substrate (Fig. 7; Table 2). The axis 
375 of PC4 was generally related to depth at the first metatarsal head and the hallux, relative to the

376 lateral metatarsal heads and toes (Fig. 5; Table 1). Mixed effects modeling revealed significant

377 effects of substrate deformability, and also the relative amount of pressure along the transverse

378 toe-off axis of the foot (mean of peak pressures on the first and second metatarsal heads minus

379 mean of peak pressures on second through fifth metatarsal heads) on variation along PC4 (Fig. 7;

380 Table 2). Finally, the fifth principal component axis described depth at the lateral midfoot and

381 second toe relative to depth at the fifth toe (Fig. 5; Table 1). This component was significantly

382 influenced by gait type, the angle of the ankle at toe-off, and the deformability of the substrate

383 (Fig. 7; Table 2). In each of these linear models gait type was not collinear with mean footprint

384 depth, which was used as the proxy for substrate deformability. This result supports the

385 hypothesis that, at least in this study, variation in the average depth across entire footprints more 386 closely reflected the mechanical properties of the substrate than the total amount of force applied 387 beneath the foot.

\section{Discussion}

The results of this study demonstrate that biomechanical variables related to lower limb

395 kinematics leave discernible signatures in the morphology of human footprints, which is

396 encouraging for the potential of fossil hominin footprints to afford a better understanding of the

397 evolution of human bipedalism. Large-scale joint motion patterns tended to show stronger 
relationships with principal axes of footprint topographic variation than did finer-scale biomechanical variables such as regional peak plantar pressure measurements. These results provide further evidence that the inference of functional patterns from footprint morphologies is much more complex than simply relating deep impressions to high normal forces.

Perhaps most importantly, this experimental study found that distinct patterns of variation in footprint morphology can be linked to certain movement patterns across the lower limb. The second principal component axis of footprint shape variation was related to motion at the hip joint, the fourth was driven by foot motion, and the fifth was influenced by motion at the ankle (Fig. 7; Table 2). These relationships provide novel insight into how an entire sequence of lower limb motions can be reflected in different ways by the morphology of a footprint.

The statistically significant relationships observed here between biomechanical variables and principal components of footprint topographic variance are unlikely to be mere statistical coincidences given that the linear models were based on a priori hypotheses of biomechanical variables that could induce particular patterns of footprint shape variation. For example, the pattern of variation described by PC2, which essentially captures depth at the forefoot relative to the heel, was hypothesized to be affected by hip excursion because it influences how far forward the body's center of mass travels before the foot leaves the ground. With a high magnitude of hip excursion during the second half of stance phase, the foot leaves the ground as the center of mass is far ahead of the ground contact point and one would expect that in such a scenario a relatively higher load would be generated through the forefoot compared to the heel. There could very well be different anatomical, biomechanical, or substrate mechanical variables that influence particular patterns of footprint shape variation that were not quantified and included in our models. Yet certain biomechanical variables do seem to have strong relationships with particular 
421 patterns of footprint shape variation, and these relationships would be expected to be consistent

422 even outside of this human sample.

This study also provides a new quantitative understanding of the ways in which certain

424 patterns of human footprint topographic variation, and relationships between human locomotor

425 biomechanics and footprint shape, are influenced by substrate mechanics. The results

426 demonstrate that most patterns of footprint shape variation that are related to biomechanical

427 variables are also sensitive to the amount of substrate displaced in a particular trial (this was the

428 case for the first, fourth, and fifth principal component axes; Table 2). Furthermore, substrate

429 deformability appeared to be solely responsible for variation along the third principal component

430 axis of human footprint topographic variance which reflected the relative amount of deformation

431 along an anteroposterior axis (heel/toe versus midfoot/metatarsal heads).

432

Bates and colleagues (2013), and also Morse and colleagues (2013), found that footprints

433 in more deformable sediments tended to have deeper forefoot than heel impressions. That result

434 corresponds well with the model describing variation along the first principal component axis of

435 footprint topographic variance in this study. However, this study also found the pattern of shape

436 variation (i.e., PC1) to be significantly influenced by gait type (Table 1). This study did not

437 identify a clear 'change point' in footprint depth at which the primary influence on PC1 shifted

438 from a biomechanical to a substrate mechanical effect, although Bates and colleagues (2013)

439 proposed that such a transition may occur once footprints exceed $20 \mathrm{~mm}$ in depth.

$440 \quad$ It is interesting to note that while the effects of substrate compliance on patterns of

441 variation in footprint morphology were statistically significant, their effects were typically in the

442 same direction as the effects of biomechanical variables but of a smaller magnitude. First, this

443 means that one can more confidently compare functional signals preserved in different footprints 
444 so long as they are of comparable overall depths. If, for example, one came across two trails of 445 footprints with similar stride lengths and similar overall depth, but one had a much deeper 446 forefoot relative to heel impression than the other, then it is likely that differences in gait type

447 produced those morphological differences. The reason for this is that the magnitude of the effect 448 of gait type on PC1 is much greater (about three times greater) than the magnitude of the effect 449 of sediment deformability. One would have to be much more cautious though in developing 450 functional interpretations in cases where footprints differ significantly in their depths.

Second, the fact that substrate and biomechanical effects act in similar directions could 452 also reflect relationships between bipedal biomechanics and substrate compliance. For example, 453 one could tend to use an 'exaggerated' medial transfer of pressure as substrates become more 454 compliant. The exact relationships between human biomechanics and substrate compliance, and 455 their effects on footprint morphology, are relatively under-studied. However, simulation studies 456 of the formation of theropod tracks have shed important light on this issue, and have revealed 457 that differences in substrate properties can cause footprint morphologies to be misleadingly 458 suggestive of locomotor differences (Falkingham et al., 2011).

Some of the variables that significantly influence patterns of variation in footprint 462 morphology directly contribute to certain definitions of 'human-like' bipedalism. For example, 463 much debate has surrounded the reconstruction of early hominin limb joint postures during 464 bipedal locomotion, and conflicting ideas exist regarding whether or not early hominins were 465 capable of walking with a human-like posture. Based on skeletal anatomy, some researchers 466 have argued that members of the genus Australopithecus likely employed somewhat compliant 
467 bipedal gaits, and walked upright with greater degrees of hip and knee flexion than modern

468 humans do today (e.g., Stern and Susman, 1983; Schmitt, 2003). Others contend that the hip and

469 lower limb anatomy of Australopithecus would not have precluded them from fully upright,

470 human-like bipedalism (e.g., Lovejoy et al., 1973). These conflicting results and interpretations

471 continue due to the lack of clear skeletal signatures of the habitual motion patterns employed by

472 these early hominins during their bipedal locomotion. Previous research has demonstrated that

473 the footprints of humans walking with normal and compliant (bent-hip-bent-knee) gaits can be

474 distinguished, and that the c.3.7 Ma presumed Australopithecus footprints from Laetoli more

475 closely resemble those produced with extended limbs (Raichlen et al., 2010). This study has built

476 upon those results by showing that hip, and ankle joint motions are reflected in specific patterns

477 of footprint shape variation (specifically in the second and fifth principal component axes of

478 human footprint shape variation) within a large sample of humans who were all walking with

479 their normal extended limb gaits. This implies that even more subtle differences in lower limb

480 kinematics could be detected from the footprints of fossil hominins. Given the known influence

481 of even minor changes to limb compliance on locomotor energetics (e.g., Pontzer et al., 2009)

482 this could lead to the development of new hypotheses regarding the metabolic costs of bipedal

483 locomotor patterns employed by fossil hominins at various footprint sites.

484 Additionally, the results of this study show that a specific feature that is diagnostic of

485 human foot function, the transfer of plantar pressure to the medial metatarsal heads for

486 propulsion, can be detected within one specific pattern of footprint shape variation (along the

487 fourth principal component axis). This pattern of foot function is unique to humans compared to

488 other primates who occasionally walk bipedally, including chimpanzees (Elftman and Manter,

489 1935), bonobos (Vereecke et al., 2003), gibbons (Vereecke et al., 2005), and possibly orangutans 
490 and gorillas (Crompton et al., 2012). The medial transfer of pressure allows humans to use their 491 hallux for propulsion. Other primates do not exhibit such a pattern when walking on the ground

492 because their halluces are adapted primarily for grasping during arboreal locomotion. Earlier

493 researchers have suggested that the relatively shallow depth in the region of the first metatarsal

494 head among the Laetoli hominin footprints may reflect a pattern of foot function that differs from

495 what is seen in modern humans (e.g., Stern and Susman, 1983; Schmid, 2004; Bennett et al., 496 2009; but see White and Suwa, 1987). This study provides a better understanding of how the

497 human toe-off mechanism is reflected in human footprint topography, and offers a framework for 498 testing whether or not fossil hominin footprint morphologies fit within the human range of 499 variation.

500 It is important to consider though how the results presented here can specifically be 501 applied to analyses of fossil hominin footprints. As with any modeling approach, significant 502 relationships merely inform us of how well the experimental data fit a particular linear model 503 that we specify. These are not absolute, causal relationships. However, the significant 504 relationships that we have uncovered can be used to suggest how different footprint shapes may 505 reflect particular functional patterns. For example, if one were to uncover a trackway of fossil 506 hominin footprints where traveling speed can be estimated from stride length, they could be 507 compared to human tracks produced at similar speeds, on similar substrates, and of similar 508 overall depths. In such a comparison, if the fossil hominin track were shown to have markedly 509 deeper hallux and second toe impressions than the average human footprint, one could 510 hypothesize that the hominin who created that track likely used a greater amount of hip retraction 511 than the average human (based on the relationship between PC2 - which reflects relative medial 512 toe to heel depth - and hip retraction). Of course if this interpretation coincides with other lines 
513 of supporting evidence, such as morphological data, of the taxa presumed to have produced the

514 footprint then one can make a stronger case for the functional interpretation of the tracks.

516 Limitations of this study for the analysis of fossil hominin tracks

517 This study does not provide any predictive models through which one could generate a

518 prediction of the exact joint movements (e.g., $x$ degrees of knee flexion) used by the hominin

519 who produced a particular track. Future work in this direction, which could build on the results

520 found here, would be very fruitful and may provide new avenues for interpreting biomechanics

521 from fossil hominin footprints. Furthermore, one should be wary of confounding effects of speed

522 and substrate on footprint morphology that were not explicitly accounted for in this experimental

523 design. Interpretations of fossil hominin footprints based on these results should be, at the least,

524 limited to comparisons that involve footprints created at similar speeds and of similar overall

525 depths.

526

527 Conclusions

528 The results of the study presented here offer a novel quantitative framework from which

529 to understand how biomechanical variables related to locomotor patterns are expressed in human

530 footprint morphological variation. But they also offer a new understanding of some of the ways

531 in which a substrate’s mechanical properties influence the expression of biomechanical variables

532 in footprints, and reveal patterns of footprint shape variation that do not appear to be

533 biomechanically relevant. These results offer a framework that can be used, with appropriate

534 caution, for developing biomechanical hypotheses from comparisons of fossil hominin footprint

535 morphologies. 
By building upon this understanding of how 'human-like' patterns of bipedalism manifest

537

themselves in footprint morphological variation, fossil hominin footprints can be used in new ways to better understand detailed similarities or differences in the locomotion of different extinct hominin taxa. This experimental study provides the first means for quantitative, rather than qualitative, interpretations of locomotor patterns represented by different footprint assemblages. The linear mixed effects models presented here are characterized by relatively high residuals (Table 2) and therefore future work should pursue the development of robust predictive models from which one could generate more specific and more accurate predictions of the biomechanical pattern being expressed by a given footprint assemblage (e.g., the exact angles, +/- prediction error, of joints across the lower limb throughout a stride). However, the quantitative framework established here will allow comparisons to be made between different sets of fossil hominin footprints. It will also support the development of new hypotheses about how footprint morphologies reflect specific aspects of the locomotor patterns that produced them.

\section{Acknowledgements}

David Green and Matt Ferry are thanked for their direct contributions to experimental data collection during this project. We thank Mark Teaford, Jeremy DeSilva, Matt Tocheri, Bernard Wood, and two anonymous reviewers for discussions and comments that improved this project and the associated manuscript. We would like to thank David Braun, Jack Harris, Purity Kiura, Emmanuel Ndiema, participants in the Koobi Fora Field School, the National Museums of Kenya, the town of Ileret, Kenya, and the local Daasanach volunteers for their contributions to this research. This study was funded by the Leakey Foundation, the National Science Foundation 
(BCS-1128170, BCS-1232522, BCS-1515054, DGE-080163, SMA-1409612), the Wenner-Gren

560 Foundation, and The George Washington University’s Centers and Institutes Facilitating Fund,

561 George Gamow Fellowship, and Office of the Vice President of Research Undergraduate

562 Fellowship.

563

564 References

565 Barnett, C.H., 1962. The normal orientation of the human hallux and the effect of footwear. J.

566 Anat. 96, 489-494.

567 Bates, K.T., Savage, R., Pataky, T.C., Morse, S.A., Webster, E., Falkingham, P.L., Ren, L., Qian, 568 Z., Collins, D., Bennett, M.R., McClymont, J., Crompton, R.H., 2013. Does footprint depth

569 correlate with foot motion and pressure? J. R. Soc. Interface 10, 20130009.

570 Behrensmeyer, A.K., 2011. Conversations with Glynn's ghost: the evolution of paleolandscape

571 research at East Turkana. In: Sept, J., Pilbeam, D. (Eds.), Casting the Net Wide: Papers in Honor 572 of Glynn Isaac and his Approach to Human Origins Research. Oxbow Books, Cambridge, pp.

$573 \quad 21-40$.

574 Bennett, M.R., Harris, J.W., Richmond, B.G., Braun, D.R., Mbua, E., Kiura, P., Olago, D., 575 Kibunjia, M., Omuombo, C., Behrensmeyer, A.K., Huddart, D., Gonzalez, S., 2009. Early 576 hominin foot morphology based on 1.5-million-year-old footprints from Ileret, Kenya. Science $577 \quad 323,1197-1201$.

578 Berge, C., Penin, X., Pellé, É., 2006. New interpretation of Laetoli footprints using an 579 experimental approach and Procrustes analysis: Preliminary results. C. R. Palevol 5, 561-569. 580 Bosch, K., Gerß, J., Rosenbaum, D., 2010. Development of healthy children’s feet - Nine-year 581 results of a longitudinal investigation of plantar loading patterns. Gait Posture 32, 564-571. 
582 Crompton, R.H., Pataky, T.C., Savage, R., D'Aout, K., Bennett, M.R., Day, M.H., Bates, K., 583 Morse, S., Sellers, W.I., 2012. Human-like external function of the foot, and fully upright gait, 584 confirmed in the 3.66 million year old Laetoli hominin footprints by topographic statistics, 585 experimental footprint-formation and computer simulation. J. R. Soc. Interface 9, 707-719. 586 D’Aout, K., Pataky, T.C., De Clercq, D., Aerts, P., 2009. The effects of habitual footwear use: 587 foot shape and function in native barefoot walkers. Footwear Science 1, 81-94.

588 D'Aout, K., Meert, L., Van Gheluwe, B., De Clercq, D., Aerts, P., 2010. Experimentally 589 generated footprints in sand: Analysis and consequences for the interpretation of fossil and 590 forensic footprints. Am. J. Phys. Anthropol. 141, 515-525.

591 Darwin, C., 1871. The Descent of Man, and Selection in Relation to Sex. J. Murray, London. 592 Day, M.H., Wickens, E.H., 1980. Laetoli Pliocene hominid footprints and bipedalism. Nature $593 \quad 286,385-387$.

594 Dingwall, H.L., Hatala, K.G., Wunderlich, R.E., Richmond, B.G., 2013. Hominin stature, body 595 mass, and walking speed estimates based on 1.5 million-year-old fossil footprints at Ileret, 596 Kenya. J. Hum. Evol. 64, 556-568.

597 Drapeau, M.S., Harmon, E.H., 2013. Metatarsal torsion in monkeys, apes, humans and 598 australopiths. J. Hum. Evol. 64, 93-108.

599 Elftman, H., Manter, J., 1935. Chimpanzee and human feet in bipedal walking. Am. J. Phys. 600 Anthropol. 20, 69-79.

601 Falkingham, P.L., Bates, K.T., Margetts, L., Manning, P.L., 2011. The ‘Goldilocks’ effect: 602 preservation bias in vertebrate track assemblages. J. R. Soc. Interface 8, 1142-1154. 
Haile-Selassie, Y., Latimer, B.M., Alene, M., Deino, A.L., Gibert, L., Melillo, S.M., Saylor, B.Z., Scott, G.R., Lovejoy, C.O., 2010. An early Australopithecus afarensis postcranium from Woranso-Mille, Ethiopia. Proc. Natl. Acad. Sci. 107, 12121-12126.

Haile-Selassie, Y., Saylor, B.Z., Deino, A., Levin, N.E., Alene, M., Latimer, B.M., 2012. A new hominin foot from Ethiopia shows multiple Pliocene bipedal adaptations. Nature 483, 565-569. Hatala, K.G., Dingwall, H.L., Wunderlich, R.E., Richmond, B.G., 2013. The relationship between plantar pressure and footprint shape. J. Hum. Evol. 65, 21-28.

Hennig, E.M., Staats, A., Rosenbaum, D., 1994. Plantar pressure distribution patterns of young school children in comparison to adults. Foot Ankle Int. 15, 35-40.

Hoffmann, P., 1905. Conclusions drawn from a comparative study of the feet of barefooted and shoe-wearing peoples. Am. J. Orthop. Surg. 3, 105-136.

Johanson, D.C., Lovejoy, C.O., Kimbel, W.H., White, T.D., Ward, S.C., Bush, M.E., Latimer, B.M., Coppens, Y., 1982. Morphology of the Pliocene partial hominid skeleton (A.L. 288-1) from the Hadar Formation, Ethiopia. Am. J. Phys. Anthropol. 57, 403-451.

Jungers, W.L., 1982. Lucy's limbs: skeletal allometry and locomotion in Australopithecus afarensis. Nature 297, 676-678.

Lamarck, J.B.P.A., 1809. Philosophie Zoologique. Paris.

Latimer, B., Lovejoy, C.O., 1989. The calcaneus of Australopithecus afarensis and its implications for the evolution of bipedality. Am. J. Phys. Anthropol. 78, 369-386.

Latimer, B., Lovejoy, C.O., 1990a. Hallucal tarsometatarsal joint in Australopithecus afarensis. Am. J. Phys. Anthropol. 82, 125-133.

Latimer, B., Lovejoy, C.O., 1990b. Metatarsophalangeal joints of Australopithecus afarensis. Am. J. Phys. Anthropol. 83, 13-23. 
626 Leakey, M.D., Hay, R.L., 1979. Pliocene footprints in the Laetolil beds at Laetoli, northern

627 Tanzania. Nature 278, 317-323.

628 Lovejoy, C.O., Heiple, K.G., Burstein, A.H., 1973. The gait of Australopithecus. Am. J. Phys.

629 Anthropol. 38, 757-780.

630 Morse, S.A., Bennett, M.R., Liutkus-Pierce, C., Thackeray, F., McClymont, J., Savage, R.,

631 Crompton, R.H., 2013. Holocene footprints in Namibia: the influence of substrate on footprint

632 variability. Am. J. Phys. Anthropol. 151, 265-279.

633 Oxnard, C., 1975. Uniqueness and Diversity in Human Evolution. The University of Chicago

634 Press, Chicago.

635 Pontzer, H., 2012. Ecological energetics in early Homo. Curr. Anthropol. 53, S346-S358.

636 Pontzer, H., Raichlen, D.A., Sockol, M.D., 2009. The metabolic cost of walking in humans,

637 chimpanzees, and early hominins. J. Hum. Evol. 56, 43-54.

638 Putti, A.B., Arnold, G.P., Abboud, R.J., 2010. Foot pressure differences in men and women. Foot 639 Ankle Surg. 16, 21-24.

640 Raichlen, D.A., Gordon, A.D., Harcourt-Smith, W.E., Foster, A.D., Haas, W.R., 2010. Laetoli

641 footprints preserve earliest direct evidence of human-like bipedal biomechanics. PLoS One 5, 642 e9769.

643 Richmond, B.G., Aiello, L.C., Wood, B.A., 2002. Early hominin limb proportions. J. Hum. Evol. $644 \quad 43,529-548$.

645 Richmond, B.G., Hatala, K.G., Dingwall, H.L., Wunderlich, R.E., 2012. Using modern taxa to 646 understand biomechanical variables: Interpreting function from fossil footprints. Am. J. Phys. 647 Anthropol. S54, 249. 
648 Richmond, B.G., Hatala, K.G., Behrensmeyer, A.K., Bobe, R., Braun, D.R., Dingwall, H.L., 649 Green, D.J., Kiura, P., Ostrofsky, K., Roach, N.T., Villmoare, B.A., Wunderlich, R.E., Harris, 650 J.W.K., 2014. Hominin size, behavior, and ecology based on 1.5-million-year-old footprint 651 assemblages from Ileret, Kenya. Am. J. Phys Anthropol. S58, 221.

652 Robinson, J. T., 1972. Early Hominid Posture and Locomotion. The University of Chicago Press, 653 Chicago.

654 Ruff, C.B., 2009. Relative limb strength and locomotion in Homo habilis. Am. J. Phys. 655 Anthropol. 138, 90-100.

656 Ruff, C.B., 2010. Body size and body shape in early hominins - implications of the Gona pelvis. 657 J. Hum. Evol. 58, 166-178.

658 Ruff, C.B., Walker, A., 1993. Body size and body shape. In: Walker, A., Leakey, R.E. (Eds.), 659 The Nariokotome Homo erectus Skeleton. Harvard University Press, Cambridge, Massachusetts, 660 pp. 234-265.

661 Schmid, P., 2004. Functional interpretation of the Laetoli footprints. In: Meldrum, D.J., Hilton, 662 C.E. (Eds.), The Emergence of Modern Human Walking, Running, and Resource Transport. 663 Kluwer Academic/Plenum Publishers, New York, pp. 49-62.

664 Schmitt, D., 2003. Insights into the evolution of human bipedalism from experimental studies of 665 humans and other primates. J. Exp. Biol. 206, 1437-1448.

666 Sim-Fook, L., Hodgson, A.R., 1958. A comparison of foot forms among the non-shoe and shoe667 wearing Chinese population. J. Bone Joint Surg. 40-A, 1058-1062.

668 Simpson, S.W., Quade, J., Levin, N.E., Butler, R., Dupont-Nivet, G., Everett, M., Semaw, S., 669 2008. A female Homo erectus pelvis from Gona, Ethiopia. Science 322, 1089-1092. 
670 Simpson, S.W., Quade, J., Levin, N.E., Semaw, S., 2014. The female Homo pelvis from Gona:

671 Response to Ruff (2010). J. Hum. Evol. 68, 32-35.

672 Spoor, F., Wood, B., Zonneveld, F., 1994. Implications of early hominid labyrinthine

673 morphology for evolution of human bipedal locomotion. Nature 369, 645-648.

674 Stern, J.T., Susman, R.L., 1983. The locomotor anatomy of Australopithecus afarensis. Am. J.

675 Phys. Anthropol. 60, 279-317.

676 Trinkaus, E., Shang, H., 2008. Anatomical evidence for the antiquity of human footwear:

677 Tianyuan and Sunghir. J. Archaeol. Sci. 35, 1928-1933.

678 Unger H., Rosenbaum, D., 2004. Gender-specific differences of the foot during the first year of 679 walking. Foot Ankle Int. 25, 582-587.

680 Vereecke, E., D'Aout, K., De Clercq, D., Van Elsacker, L., Aerts, P., 2003. Dynamic plantar 681 pressure distribution during terrestrial locomotion of bonobos (Pan paniscus). Am. J. Phys.

682 Anthropol. 120, 373-383.

683 Vereecke, E., D'Aout, K., Van Elsacker, L., De Clercq, D., Aerts, P., 2005. Functional analysis

684 of the gibbon foot during terrestrial bipedal walking: plantar pressure distributions and three-

685 dimensional ground reaction forces. Am. J. Phys. Anthropol. 128, 659-669.

686 Walker, A., Leakey, R.E., 1993. The postcranial bones. In: Walker, A., Leakey, R.E. (Eds.), The

687 Nariokotome Homo erectus Skeleton. Harvard University Press, Cambridge, Massachusetts, pp. $68895-160$.

689 Ward, C.V., 2002. Interpreting the posture and locomotion of Australopithecus afarensis: Where 690 do we stand? Am. J. Phys. Anthropol. 119, 185-215.

691 Ward, C.V., Kimbel, W.H., Johanson, D.C., 2011. Complete fourth metatarsal and arches in the 692 foot of Australopithecus afarensis. Science 331, 750-753. 
693 Wells, L.H., 1931. The foot of the South African native. Am. J. Phys. Anthropol. 15, 185-289.

694 White, T.D., Suwa, G., 1987. Hominid footprints at Laetoli: facts and interpretations. Am. J.

695 Phys. Anthropol. 72, 485-514.

696 Wood, B., Richmond, B.G., 2000. Human evolution: taxonomy and paleobiology. J. Anat. 196, $697 \quad 19-60$.

698 Wunderlich, R.E., Cavanagh, P.R., 2001. Gender differences in adult foot shape: implications for 699 shoe design. Med. Sci. Sport Exer. 33, 605-611.

700 Zuur, A.F., Ieno, E.N., Walker, N., Saveliev, A.A., Smith, G.M., 2009. Mixed Effects Models 701 and Extensions in Ecology with R. Springer, New York.

702

$703 \quad$ Figure legends

704 Figure 1: Lateral photograph of volunteer performing footprint formation experiments. Subjects 705 passed over a trackway approximately 20 meters in length, and in the center of this trackway 706 were both a plantar pressure pad and a pit filled with hydrated sediment from a layer which 707 preserved 1.5-million-year-old fossil hominin footprints at Ileret, Kenya. Trials were discarded 708 and repeated if subjects visibly altered their gait to 'target' any part of the apparatus along this 709 trackway.

710

711 Figure 2: Stratigraphic section of FwJj14E site at Ileret, Kenya, with labeled locations of fossil

712 hominin footprint layers (figure from Dingwall et al., 2013; adapted from Behrensmeyer, 2011).

713 The sediment used in these experiments came from the layer which contains "FLT 1"; all

714 footprint surfaces in this section are typologically very similar. 
716 Figure 3: Image of 3-dimensional footprint model with markers identifying the regions from

717 which footprint depths were measured. These regions mirrored those from which plantar

718 pressure measurements were taken, but with an additional depth measurement taken from the

719 medial midfoot (an area that typically did not experience any pressure when subjects walked

720 across the firm pressure pad). All depth measurements were normalized in the same way as those

721 of plantar pressure.

722

723 Figure 4: Scree plot showing the proportion of variance (y-axis) explained by the first ten

724 principal component axes describing variation in the 14 regional measurements of footprint 725 depth.

726

727 Figure 5: Bar plots showing the rotations which were applied to the 14 original footprint depth

728 measurements in order to produce each of the first five principal components of footprint 729 topographic variation. Positive loadings on a given axis are plotted in dark grey, while negative 730 loadings are plotted in light grey.

731

732 Figure 6: Demonstrative boxplot of PC1 values (y-axis) and gait type (x-axis). This plot 733 represents one experimental subject, allowing for easier visualization of the significant effect of 734 gait type on PC1. The mixed effects models include random intercepts for individual subjects but 735 the value of the slope (the magnitude of the effect) is calculated across all subjects. A summary 736 of the model describing variation in PC1 across all subjects can be found in Table 2. 
738 Figure 7: Demonstrative plots, from individual subjects, of PC2-5 values (y-axis) and different 739 variables that have significant effects on those principal components (x-axis). As in Figure 6, 740 these plots each show data from only one subject, to improve visualization of the significant 741 fixed effects. Summaries of the models describing variation in PC2-5 across all subjects can be 742 found in Table 2. These mixed effects models include random intercepts for individual subjects 743 but values of the slope (magnitudes of the effects) are calculated across all subjects. 
fig 1

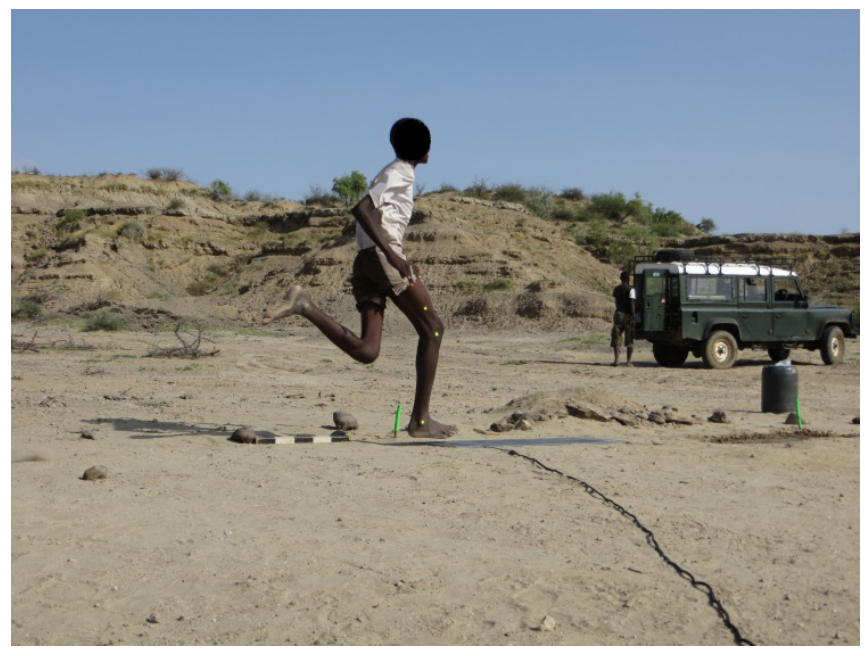


fig 2

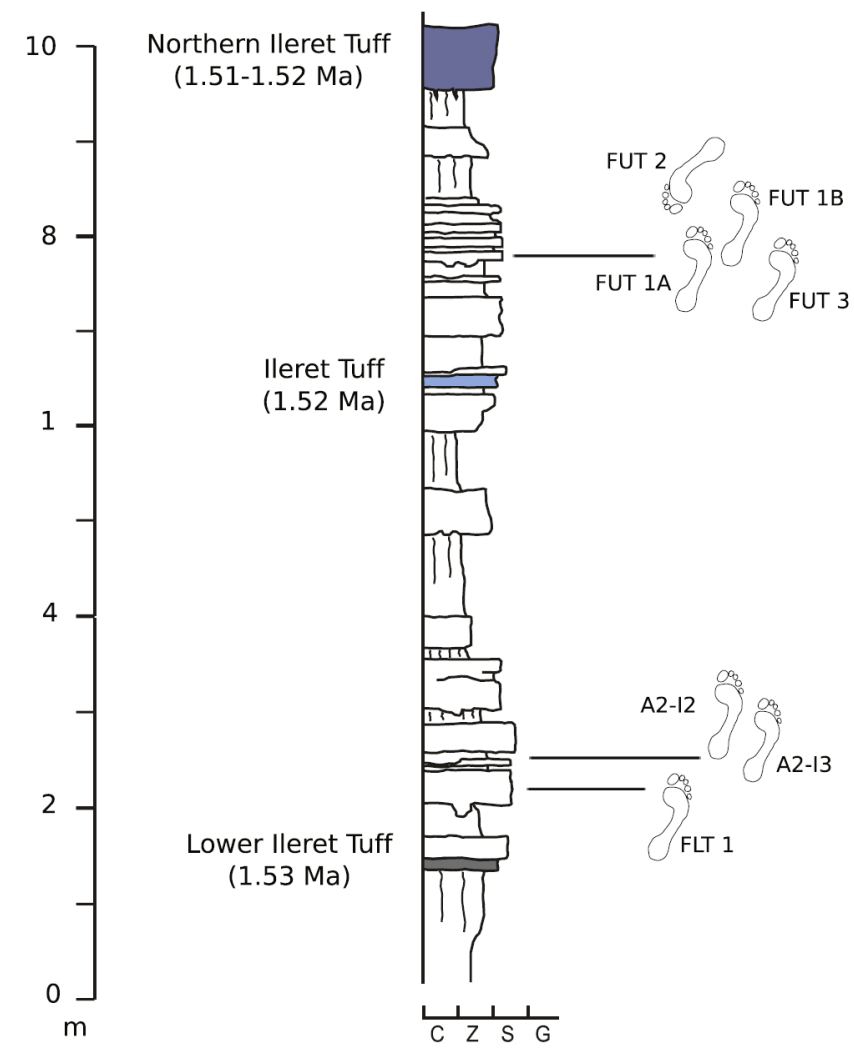


fig 3

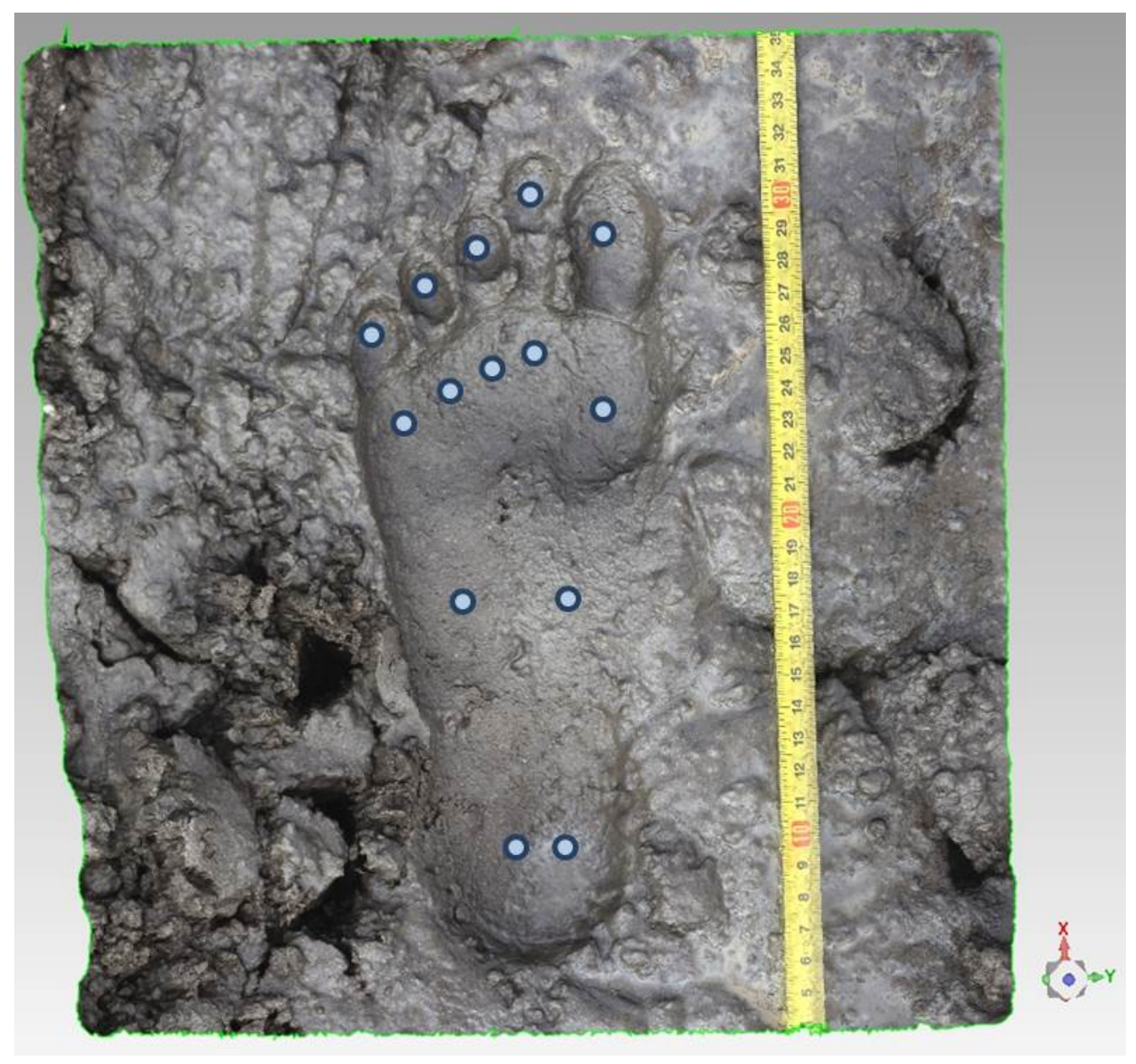



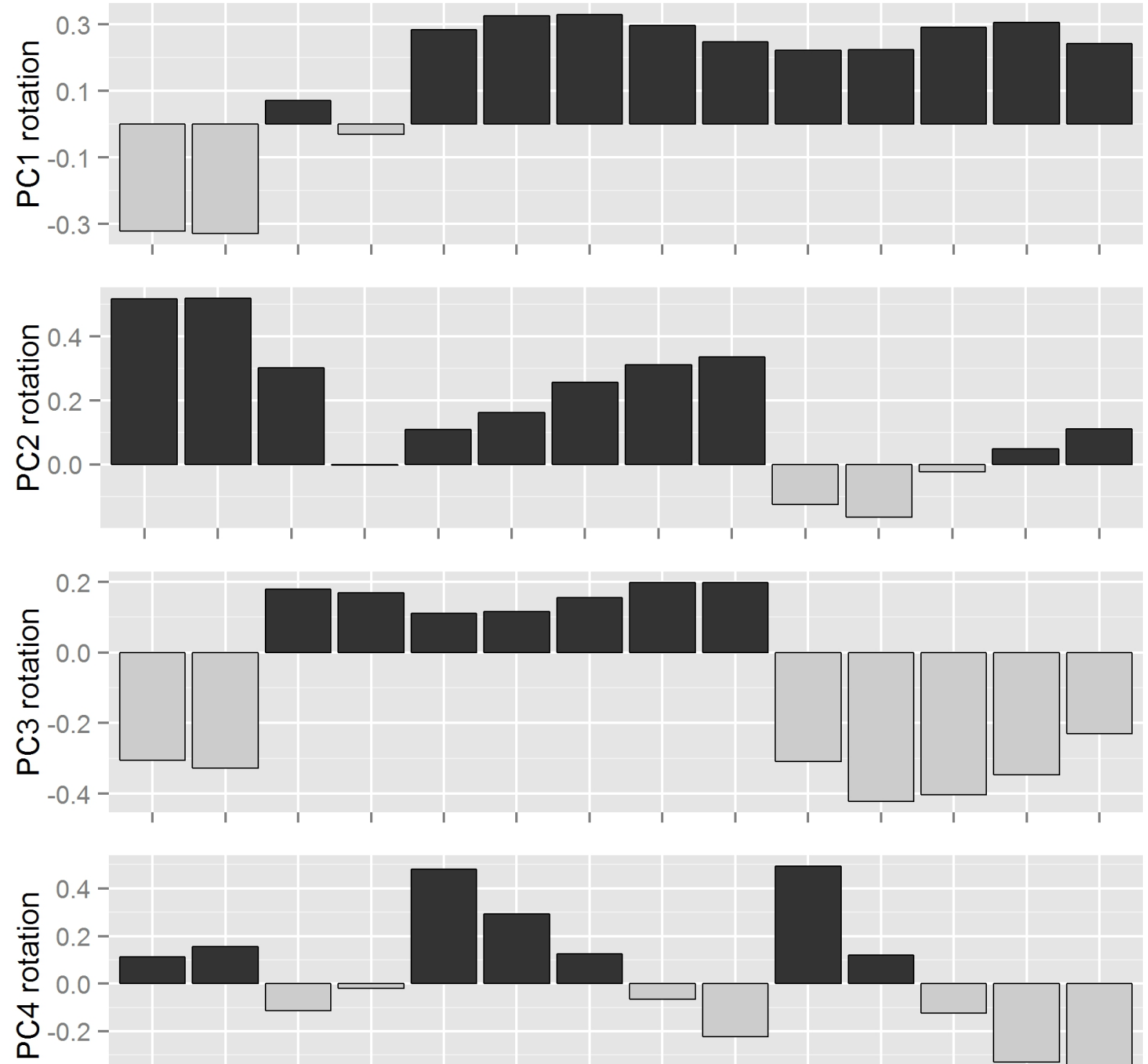
-0.4 -
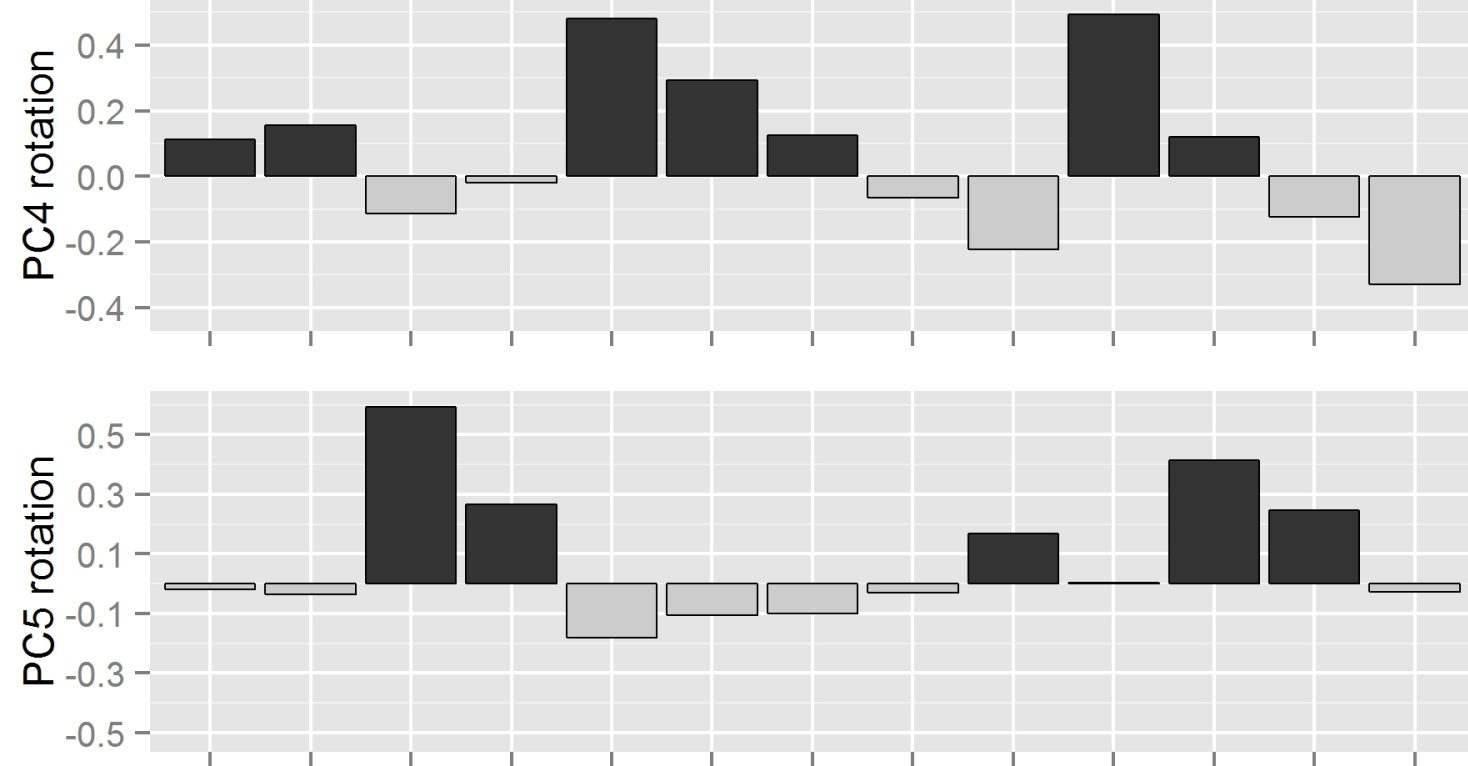

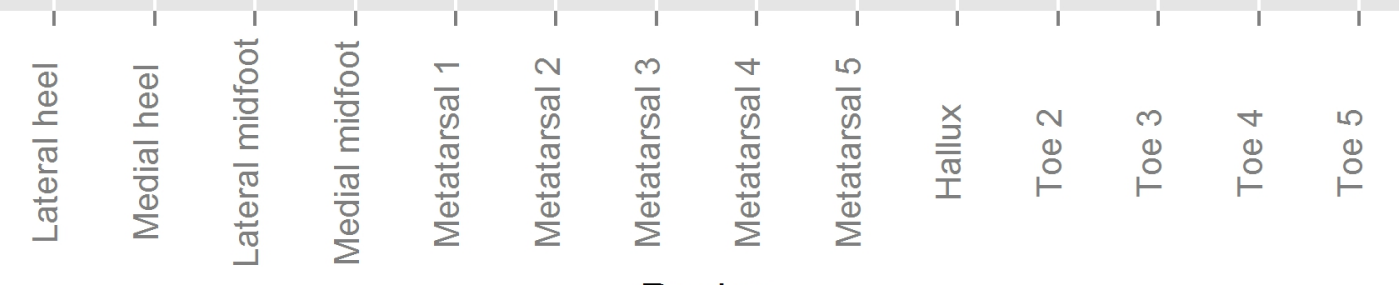


fig 6

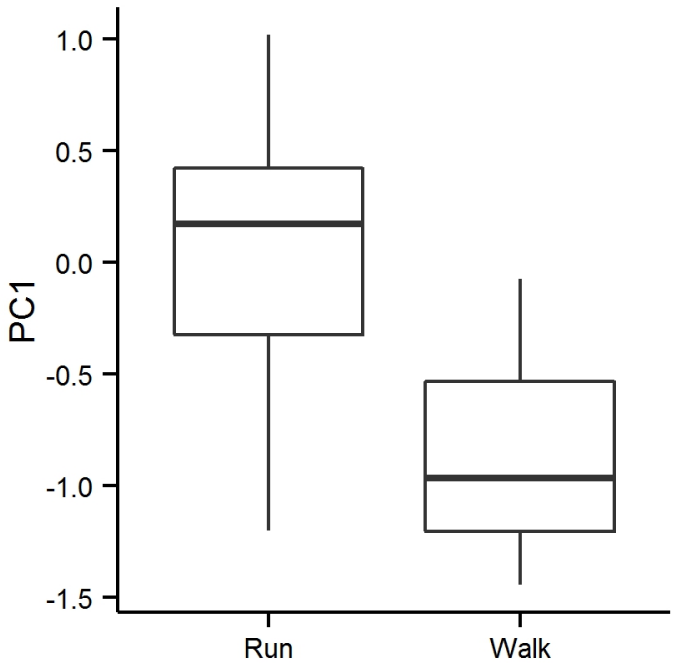



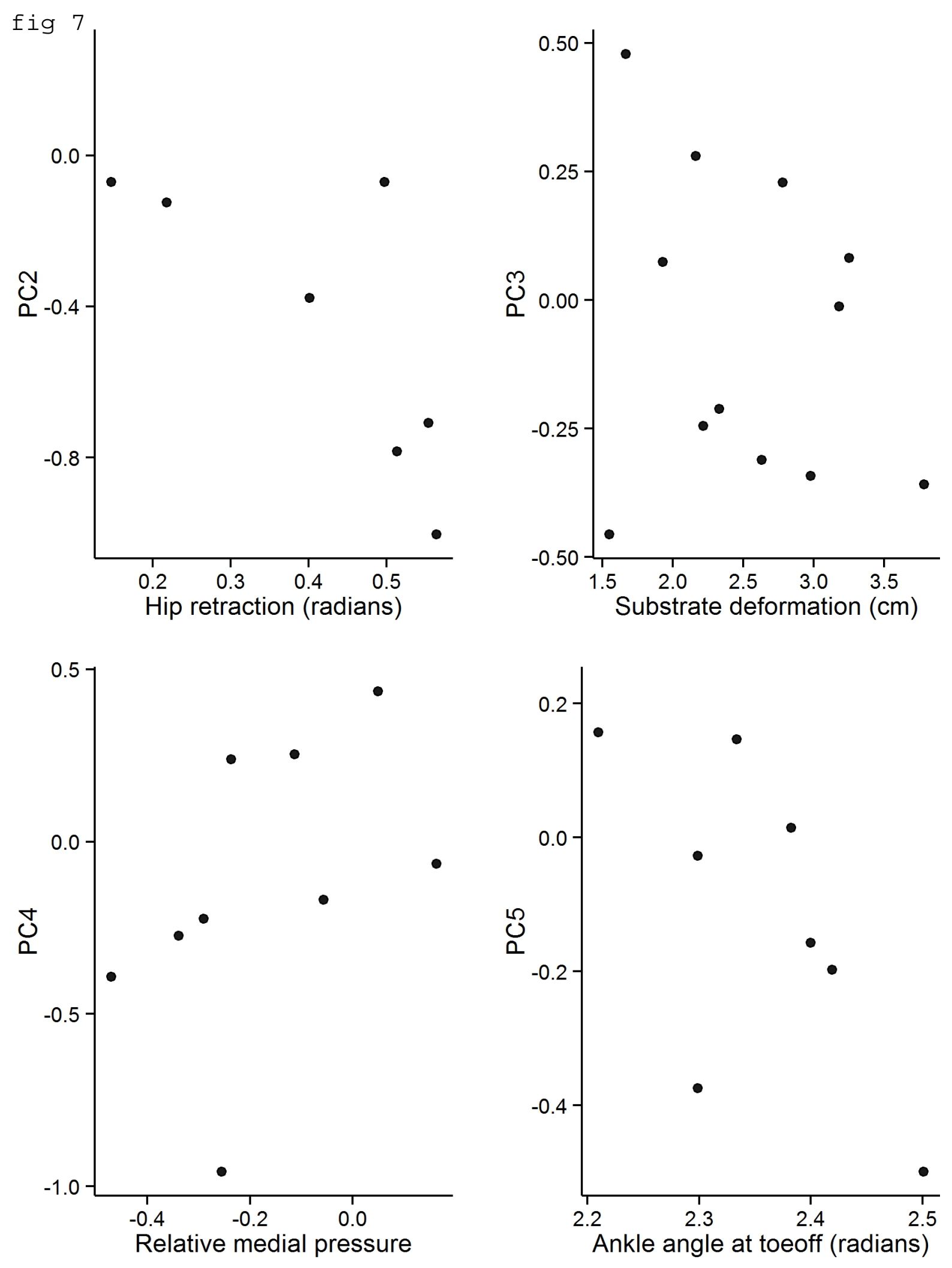
Table 1. Summary table describing the original regional depth measurements that have the largest positive and negative loadings on the first five principal components of footprint depth variation (displayed in Figure 5). Those regions listed here had loadings that exceeded either the mean positive or the mean negative loadings for the given principal component axis.

\begin{tabular}{cll}
\hline Component & Primary positive loadings & Primary negative loadings \\
\hline PC1 & Metatarsals 1-4 & Lateral and medial heel \\
& Toes 3-4 & \\
PC2 & Lateral and medial heel & Hallux \\
& Lateral midfoot & Toe 2 \\
& Metatarsals 3-4 & \\
PC3 & Lateral and medial midfoot & Toes 2-4 \\
& Metatarsals 4-5 & \\
PC4 & Metatarsals 1-2 & Metatarsal 5 \\
& Hallux & Toes 4-5 \\
& Lateral midfoot & Metatarsal 1 \\
& Toe 2 & Toe 5 \\
\hline
\end{tabular}


Table 2. Summary of linear mixed effects models describing variation along the first five principal component axes of footprint topographic variance. The original inclusive linear models considered all of the variables in the corresponding row, while the reduced models retained only the statistically significant fixed effects (see Materials and Methods).The effects of gait type are directionally calculated as the effects of a walk relative to a run; for instance walking had a negative effect on PC1 scores.

\begin{tabular}{|c|c|c|c|c|c|}
\hline Component & $\begin{array}{c}\text { Median standardized } \\
\text { residual }\end{array}$ & $\begin{array}{l}\text { Fixed effect } 1 \\
\text { (slope, } p \text {-value) }\end{array}$ & $\begin{array}{l}\text { Fixed effect } 2 \\
\text { (slope, } p \text {-value) }\end{array}$ & $\begin{array}{l}\text { Fixed effect } 3 \\
\text { (slope, } p \text {-value) }\end{array}$ & $\begin{array}{c}\text { Effects lacking } \\
\text { statistical significance }\end{array}$ \\
\hline PC1 & 0.090 & $\begin{array}{c}\text { Gait type } \\
(-0.34,<0.001)\end{array}$ & $\begin{array}{l}\text { Substrate deformability } \\
\qquad(0.12,<0.001)\end{array}$ & & $\begin{array}{l}\text { Hip excursion during first } \\
\text { half of stance; hip excursion } \\
\text { during second half of stance; } \\
\text { maximum forefoot pressure } \\
\text { relative to heel }\end{array}$ \\
\hline PC2 & 0.109 & $\begin{array}{l}\text { Hip excursion during second } \\
\text { half of stance } \\
(-0.28,0.02)\end{array}$ & & & $\begin{array}{l}\text { Gait type; peak pressure } \\
\text { beneath toes 2-5; peak } \\
\text { pressure beneath hallux; } \\
\text { substrate deformability }\end{array}$ \\
\hline PC3 & -0.003 & $\begin{array}{l}\text { Substrate deformability } \\
\qquad(-0.06,0.01)\end{array}$ & & & $\begin{array}{l}\text { Gait type; angle of hip at foot } \\
\text { strike; angle of ankle at foot } \\
\text { strike; angle of hip at toe-off; } \\
\text { angle of ankle at toe-off }\end{array}$ \\
\hline
\end{tabular}




\begin{tabular}{|c|c|c|c|c|c|}
\hline PC4 & 0.107 & $\begin{array}{l}\text { Relative pressure across } \\
\text { transverse toe-off axis } \\
\qquad(0.17,0.05)\end{array}$ & $\begin{array}{l}\text { Substrate deformability } \\
\qquad(0.06,<0.001)\end{array}$ & & $\begin{array}{l}\text { Gait type; angle of ankle at } \\
\text { toe-off }\end{array}$ \\
\hline PC5 & -0.050 & $\begin{array}{c}\text { Gait type } \\
(-0.14,<0.001)\end{array}$ & $\begin{array}{l}\text { Angle of ankle at toe-off } \\
\qquad(-0.19,0.05)\end{array}$ & $\begin{array}{l}\text { Substrate deformability } \\
\qquad(-0.04,0.02)\end{array}$ & $\begin{array}{l}\text { Relative pressure across } \\
\text { transverse toe-off axis; peak } \\
\text { pressure beneath hallux; } \\
\text { angle of ankle at toe-off }\end{array}$ \\
\hline
\end{tabular}

